\title{
Hydrodesulfurization over model sulfide cluster-derived catalysts
}

\author{
B.T. Carvill ${ }^{1}$ and L.T. Thompson* \\ Department of Chemical Engineering. The University of Michigan, Ann Arbor, MI 48109-2136 \\ (USA), tel. (+1-313)936-2015, fax. (+1-313)763-0459, e-mail Levi_Thompson \\ $@$ um.cc.umich.edu
}

(Received 10 October 1990, revised manuscript received 28 March 1991)

\begin{abstract}
There is growing interest in the use of organometallic clusters as precursors to model heterogeneous catalysts. This interest is partially derived from the expectation that "solid-state metal complex catalysts" will be uniform in composition and structure thus more amenable to characterization than catalysts prepared using conventional techniques. This research used a series of sulfide clusters as precursors to model heterogeneous catalysts in an effort to enhance our understanding of the active sites in hydrodesulfurization catalysts. Alumina supported catalysts derived from the sulfide clustcrs $\mathrm{Cp}_{2} \mathrm{Mo}_{2}(\mu$ $\mathrm{SH})_{2}(\mu-\mathrm{S})_{2}, \mathrm{Cp}_{2} \mathrm{Mo}_{2} \mathrm{Co}_{2}\left(\mu_{3}-\mathrm{S}\right)_{2}\left(\mu_{4}-\mathrm{S}\right)(\mathrm{CO})_{4}$, and $\mathrm{Cp}_{2} \mathrm{Mo}_{2} \mathrm{Fe}_{2}\left(\mu_{3}-\mathrm{S}\right)_{2}(\mathrm{CO})_{8} \quad(\mathrm{Cp}=$ cyclopentadienyl $)$ shared important catalytic and spectroscopic features with a commercial catalyst and unsupported $\mathrm{MoS}_{2}$. These strong similarities implied that the active sites in the sulfide cluster-derived catalysts could be used as models of the sites in conventionally prepared hydrodesulfurization catalysts. The active sites in the bimetallic sulfide cluster-derived catalysts appeared to be highly dispersed ensembles containing $\mathrm{Mo}^{\delta+}(\delta<4)$, cobalt or iron, and sulfur. The structure of these ensembles remains to be determined but our results provide evidence that the promotional effect in hydrodesulfurization catalysis is at least partly due to strong, direct interactions between molybdenum and the promoter. There were differences between the thiophene hydrodesulfurization product distributions. The sulfide cluster-derived catalysts produced significant amounts of $\mathrm{C}_{2}$ and $\mathrm{C}_{3}$ hydrocarbons while the commercial catalyst produced mostly $\mathrm{C}_{4}$ hydrocarbons. These results suggested that $\mathrm{C}-\mathrm{C}$ bond hydrogenolysis preceded $\mathrm{C}-\mathrm{S}$ bond cleavage over the sulfide cluster-derived catalysts. More subtle differences between the product distributions of the cluster-derived catalysts have been attributed to differences in the nature of sulfide ligands in their precursors.
\end{abstract}

Keywords: clusters, hydrodesulfurization, hydrotreatment, organometallics, sulfides.

\section{INTRODUCTION}

Hydrotreatment, the catalytic removal of poisons such as sulfur and nitrogen from crude oil is one of the most important processes in petroleum refining. Commercial hydrotreatment catalysts typically consist of molybdenum and/

${ }^{1}$ Current address: Y.N. Ipatieff Laboratory, Center for Catalysis and Surface Science, Northwestern University, Evanston, IL 60208, USA.

0166-9834/91/\$03.50 (C) 1991 Elsevier Science Publishers B.V. All rights reserved. 
or tungsten sulfides promoted with cobalt and/or nickel to enhance their activity. Despite extensive study the reasons for this promotional effect remain unclear. A better understanding of the promotional effect, the associated active sites and the reaction mechanisms might lead to catalysts with improved activities and selectivities. These improvements appear necessary for the next generation of catalysts that will be used for the hydrotreatment of sulfur-rich heavy crudes and nitrogen-rich synthetic crudes.

Several models have been proposed to describe the active site in promoted hydrodesulfurization (HDS) catalysts. These models can be categorized based on the type of interaction between molybdenum and the promoter element, $M$ (cobalt, nickel or iron). The models characterized by relatively weak, indirect interactions include the monolayer and contact synergy models. The monolayer model describes the active site as a vacancy in a two-dimensional molybdenum oxysulfide raft that is anchored to the support [1]. The role of the promoter is not clearly defined but it is believed that the promoter atoms stabilize the molybdenum oxysulfide raft and thus increase the number of vacancies. Delmon [2] proposed that a synergistic interaction occurs at the interface between separate molybdenum and cobalt or nickel sulfide phases. According to the contact synergy or remote control model, active $\mathrm{Mo}^{3+}$ sites are produced by hydrogen spillover from the promoter sulfide onto $\mathrm{MoS}_{2}$. No direct interactions between Mo and the promoter element are discussed in connection with the monolayer or contact synergy models.

Strong, direct interactions between molybdenum and the promoter atom are implied for the intercalation and "CoMoS" models. The intercalation model suggests that the promoter atoms reside between layers of the $\mathrm{MoS}_{2}$ crystallites [3]. These atoms cause a reduction of the molybdenum and an increase in activity. Closely related to the intercalation model is the "CoMoS" model. Wivel et al. [4] used in situ Mössbauer emission spectroscopy to identify "CoMoS" a species whose concentration correlated linearly with HDS activity. $\mathrm{X}$-ray absorption spectroscopic studies suggested that the cobalt atoms in this "CoMoS" species were pseudo-intercalated at the edges of $\mathrm{MoS}_{2}$-like structures [5]. The analogous "FeMoS" species has also been identified in ironmolybdenum sulfide catalysts [6]. The "CoMoS" model has gained increased acceptance over the past decade and more than any other model accounts for the important spectroscopic and catalytic properties of promoted HDS catalysts. Other less popular models of the active site have been proposed but will not be detailed here. For additional information the reader is directed to several excellent review articles [7-9].

Efforts aimed at understanding HDS catalysis most often employ catalysts prepared using conventional techniques. Supported HDS catalysts are usually prepared by the impregnation method. The appropriate metal salts are dissolved in aqueous solutions, impregnated into the pores of the support, decomposed, reduced and/or sulfided [10,11]. One of the problems faced when study- 
ing these types of catalysts is that they tend to be nonuniform, and often the predominant phase ( $\mathrm{s}$ ) is of little or no catalytic importance. For example, depending on the pretreatment conditions significant amounts of cobalt react with $\mathrm{Al}_{2} \mathrm{O}_{3}$ to produce a pseudo-aluminate. This species which is present in most conventionally prepared sulfided cobalt molybdate catalysts has no bearing on catalytic activity but shows up as a significant feature during spectroscopic characterization [9]. Characterization of single crystals and attempts to prepare single phases of the active phase show promise but have not as yet led to an unambiguous description of the active site [12-16].

In this paper we discuss the use of sulfide clusters as precursors to model heterogeneous HDS catalysts. Our interest in using cluster-derived catalysts was partially derived from the expectation that "solid-state metal complex catalysts" would be more uniform and consequently more amenable to detailed characterization and evaluation than conventionally prepared catalysts. Some degree of catalyst design can also be accomplished when discrete molecular precursors containing the desired constituents are employed. This is especially important for bimetallic catalysts where the two metals can be deposited together in relative amounts defined by the cluster composition. Finally, supported cluster catalysts provide a link between homogeneous catalysis where the catalytic complexes are easily identified, and heterogeneous catalysis where the surfaces are generally ill-defined.

A working hypothesis of this research was that the HDS activities of catalysts derived from sulfide clusters containing strong Mo-M bonds would exceed those of the monometallic sulfide cluster-derived catalysts if the promotional effect is due to direct interactions between molybdenum and the promoter atom. We know that the sulfide clusters undergo structural and chemical changes during catalyst preparation and exposure to reaction conditions, but we expected that clusters containing Mo-M bonds would produce bimetallic ensembles. Obviously monometallic precursors would not produce bimetallic ensembles. This paper also discusses the importance of molybdenum and sulfur chemistry in HDS catalysis.

In work that has been or will be published elsewhere we observed that the sulfide clusters produced highly dispersed surface ensembles. Infrared spectroscopy indicated that the sulfide clusters were supported intact $[17,18]$. Subsequent heat treatment at temperatures higher than ca. $380 \mathrm{~K}$ caused a sudden and complete loss of the infrared activity. This abrupt loss of ligands suggested that ensembles derived from the sulfide clusters were compositionally uniform. This was corroborated by Mössbauer spectroscopic examinations. Interaction of the $\mathrm{Mo}-\mathrm{Fe}$ sulfide cluster with $\gamma-\mathrm{Al}_{2} \mathrm{O}_{3}$ followed by thermal decomposition and reduction produced Mo-Fe ensembles containing almost exclusively $\mathrm{Fe}^{2+}$ $[17,19]$. The Mössbauer parameters of this species closely resembled those of the "FeMoS" phase identified by Topsøe's group. The extreme air-sensitivity 


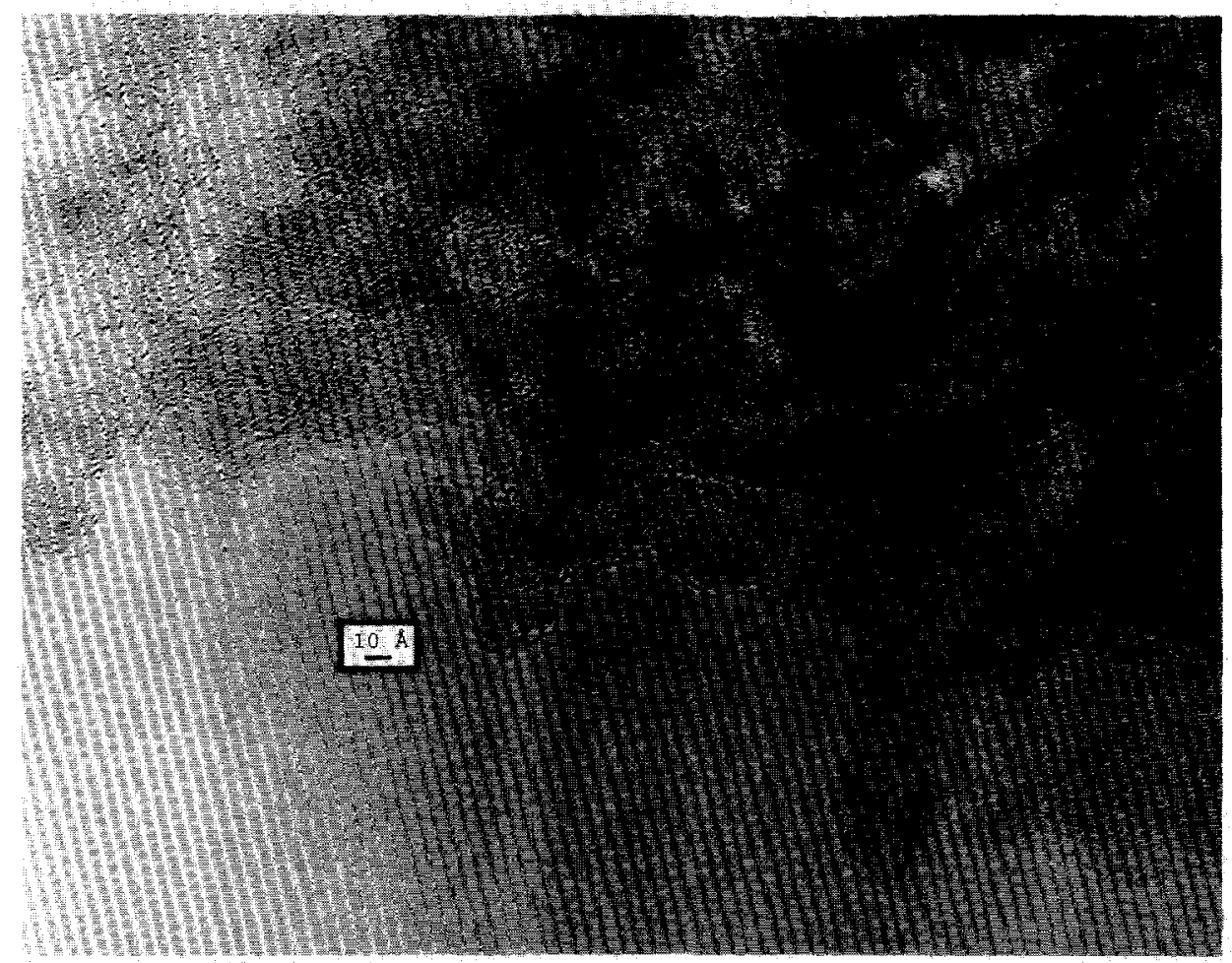

Fig. 1. High resolution electron micrograph of the $\mathrm{Mo}-\mathrm{Fe}$ sulfide cluster-derived catalyst [20]. The regular structure observed in this micrograph is due to the $\gamma-\mathrm{Al}_{2} \mathrm{O}_{3}$ support.

of the cluster-derived catalysts suggested that the ensembles resided at or very near the surface of the alumina. Structural characterization of these clusterderived ensembles might lead to a better understanding of the "FeMoS" and "CoMoS" sites. High resolution electron microscopy showed that following pretreatment and reaction at temperatures up to $673 \mathrm{~K}$ the sulfide clusterderived ensembles remained highly dispersed [20]. From micrographs including the one illustrated in Fig. 1, we concluded that the cluster-derived ensembles were less than $10 \AA \AA$ in size. Note the presence of a few very small scattering centers superimposed on the structure of the $\gamma-\mathrm{Al}_{2} \mathrm{O}_{3}$. Such scattering centers were not observed for the blank of calcined $y-\mathrm{Al}_{2} \mathrm{O}_{3}$.

\section{EXPERIMENTAL}

\section{Catalyst preparation}

A series of $\gamma-\mathrm{Al}_{2} \mathrm{O}_{3}$ supported catalysts were prepared using as precursors the sulfide clusters $\mathrm{Cp}_{2} \mathrm{Mo}_{2}(\mu-\mathrm{SH})_{2}(\mu-\mathrm{S})_{2} \quad[\mathrm{MoS}], \mathrm{Cp}_{2} \mathrm{Mo}_{2} \mathrm{Co}_{2}\left(\mu_{3}-\mathrm{S}\right)_{2}\left(\mu_{4}-\mathrm{S}\right)$ 
$(\mathrm{CO})_{4}[\mathrm{MoCoS}]$, and $\mathrm{Cp}_{2} \mathrm{Mo}_{2} \mathrm{Fe}_{2}\left(\mu_{3}-\mathrm{S}\right)_{2}(\mathrm{CO})_{8}$ [MoFeS] where $\mathrm{Cp}=$ cyclopentadienyl. These clusters were synthesized according to the procedures described by Rakowski DuBois et al. [21] and Curtis and coworkers [22, 23]. Their structures are illustrated in Fig. 2. Besides having different metal cores, there were differences between the nature of the sulfide ligands and the metal oxidation states. The MoS cluster contained hydrosulfido ligands, and the MoCoS and MoFeS clusters contained sulfido ligands. Sulfido and hydrosulfido complexes in solution are capable of interactions with hydrogen and thiols that are of fundamental importance to HDS catalysis [21, 24]. Formal oxidation states of the metals are Mo(IV) for MoS, and Mo(III) and Fe(0) for MoFeS. It is believed that the sum of the oxidation states of the metals in the MoCoS cluster add up to +8 . Some reasonable combinations include Mo(III)$\mathrm{Co}$ (I) and $\mathrm{Mo}$ (II)-Co(II). For comparison two monometallic catalysts were prepared using $\mathrm{Cp}_{4} \mathrm{Co}_{4}\left(\mu_{3}-\mathrm{S}\right)_{2}\left(\mu_{3}-\mathrm{S}_{2}\right)_{2}[\mathrm{CoS}]$ and $\mathrm{Fe}_{2}(\mu-\mathrm{S})_{2}(\mathrm{CO})_{6}[\mathrm{FeS}]$ as precursors. Details concerning the synthesis of these clusters are given elsewhere $[25,26]$.

The catalysts were prepared by the equilibrium adsorption method. The $\gamma-\mathrm{Al}_{2} \mathrm{O}_{3}$ support was prepared by calcining Catapal alumina powder for ca. $5 \mathrm{~h}$ at $773 \mathrm{~K}$ in oxygen. A solution of the desired cluster dissolved in dry $\mathrm{CH}_{2} \mathrm{Cl}_{2}$ was added to a slurry of the support in $\mathrm{CH}_{2} \mathrm{Cl}_{2}$, and the combined slurry was vigorously stirred under nitrogen for about one hour. The $\mathrm{CH}_{2} \mathrm{Cl}_{2}$ was evaporated off under vacuum at ambient temperature and the dried catalyst was stored under nitrogen for subsequent use. The nominal total metal loading was $1 \mathrm{wt}$-\%. In handling these catalysts, pain-staking efforts were made to avoid or minimize exposure to air. The resulting catalysts had surface areas of $138 \pm 19$ $\mathrm{m}^{2} / \mathrm{g}$. X-ray diffraction analysis indicated the presence of ca. $50 \AA \gamma-\mathrm{Al}_{2} \mathrm{O}_{3}$ domains and the absence of any other particles greater than $20 \AA$ in these catalysts. We also examined Katalco 477, a commercial cobalt-molybdate cat-
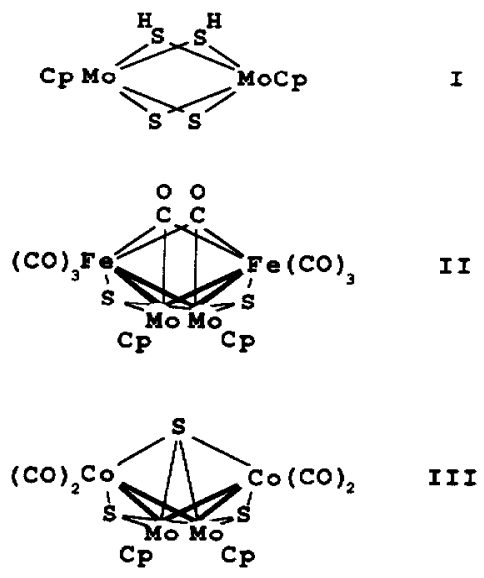

Fig. 2. Structures of the MoS (I), MoFeS (II) and MoCoS (III) sulfide clusters. Detailed ORTEP plots are given elsewhere [21-23]. 
alyst (2-5 wt.- $\%$ cobalt oxide, $12-16$ wt.- $\% \mathrm{MoO}_{3}$, and the balance aluminum oxide), and $\mathrm{MoS}_{2}$ powder (Alfa Products). The Katalco catalyst was received in the form of pellets and ground to a coarse powder.

\section{Catalytic activity measurements}

Reaction rate measurements were made using a $6.35 \mathrm{~mm}$ O.D. quartz reactor. Prepurified helium and hydrogen were further purified during passage through a commercial oxygen trap (Matheson) and a bed of activated carbon and molecular sieves. Tylan FC-260 mass flow controllers provided control of the gas flow-rates to $\pm 0.5 \mathrm{~cm}^{3} / \mathrm{min}$ standard temperature and pressure (STP). Thiophene (Aldrich $99 \%+$ purity) was introduced into the hydrogen stream using a saturator submerged in an ice/water bath (partial pressure of thiophene at $273 \mathrm{~K}$ is $2.7 \mathrm{kPa}$ ). Typically between 200 and $500 \mathrm{mg}$ of the catalysts were used. In order to maintain similar metal loadings in the reactor for each run the Katalco catalyst was diluted with inert $\mathrm{SiO}_{2}$ (Alfa Products $99.8 \%$ purity). The temperature was controlled using a thermocouple placed directly into the catalyst bed and an Omega $4002 \mathrm{KC}$ temperature controller. After loading the catalyst into the reactor, the system was quickly purged with helium. The sulfide cluster-derived catalysts were first pyrolyzed in flowing helium. These catalysts were gently heated at a rate of $1-5^{\circ} \mathrm{C} / \mathrm{min}$ to $673 \mathrm{~K}$ and held at $673 \mathrm{~K}$ for several hours. The catalysts were similarly pretreated in flowing hydrogen. There was some evidence of catalyst instability when pretreatment temperatures exceeded $773 \mathrm{~K}$, thus the maximum temperatures were limited to $673 \mathrm{~K}$ [20]. The Katalco catalyst was reduced in hydrogen at $573 \mathrm{~K}$ then sulfided in a mixture of $2 \% \mathrm{H}_{2} \mathrm{~S}$ in $\mathrm{H}_{2}$ at $673 \mathrm{~K}$ for ca. $4 \mathrm{~h}$. This protocol is similar to pretreatment schedules used for other commercial hydrotreatment catalysts $[10,11]$. The $\mathrm{MoS}_{2}$ powder was reduced in hydrogen at $673 \mathrm{~K}$ for at least $4 \mathrm{~h}$. In this work we did not explore the effects of pretreatment on the catalytic properties. However, it has been observed that the Mössbauer parameters for $\mathrm{MoFeS} / \mathrm{Al}_{2} \mathrm{O}_{3}$ pretreated in hydrogen and/or helium at temperatures greater than ca. $573 \mathrm{~K}$ were similar [19].

The reactants and products were separated using a $1.8 \mathrm{~m}$ Porasil column coated with $2 \%$ octane and analyzed using a Varian 3700 gas chromatograph. Peak areas were determined using an HP 3390A integrator. Thiophene HDS reaction rates were measured under differential conditions (thiophene conversions less than 5\%) at temperatures between 563 and $638 \mathrm{~K}$, and a total pressure of ca. $100 \mathrm{kPa}$. These rates were normalized by either the total cluster loading or the oxygen uptake. To insure the absence of transport limitations the reaction rates were measured at a variety of reactant flow-rates while maintaining constant temperature and pressure. For rates reported in this paper variations in the flow-rate did not significantly affect the product of the conversion times the flow-rate. In addition, the activities were reproduced for sub- 
sequent experiments with a different amount of catalyst. Thus we concluded that the reaction rates were free of transport limitations.

\section{Catalyst characterization}

X-ray photoelectron spectroscopy (XPS) was performed using a PHI Model 5400 ESCA spectrometer. Approximately $100 \mathrm{mg}$ of sample was pressed into a wafer and loaded into the spectrometer. Spectra were collected using aluminum $\mathrm{K} \alpha$ radiation and corrected for charging effects using the $\mathrm{Al}(2 \mathrm{p})$ peak at $74.8 \mathrm{eV}$. The XPS system had an in situ reactor so the catalysts could be reduced and/or sulfided then analyzed without exposure to air. Base vacuum in the test chamber during the collection of spectra was typically less than $3 \cdot 10^{-9}$ Torr ( 1 Torr =133.3 Pa). The system computer also contained a curve fitting package. Gaussian or Lorentzian (or combinations) peaks were deconvoluted using a non-linear least-squares algorithm overlapping.

Oxygen chemisorption permitted a comparison of the catalytic properties of the sulfide cluster-derived catalysts with those of Katalco 477 and $\mathrm{MoS}_{2}$. Because oxygen chemisorption can be corrosive, we used the pulsed adsorption technique at low temperatures $[27,28]$. These experiments were carried out using a Quantasorb sorption analyzer. Before measuring the oxygen uptake the catalyst bed was purged with helium and reduced in flowing hydrogen at $673 \mathrm{~K}$ for at least $4 \mathrm{~h}$. Note that the Katalco catalyst was presulfided in the flow reactor. The sample loop containing the catalyst was then submerged in a dry ice/acetone bath $(195 \mathrm{~K})$. Pulses of $9.98 \% \mathrm{O}_{2} / \mathrm{He}$ were passed over the catalyst until the eluted oxygen peak area was constant. This was taken as an indication that the surface was saturated. Often nitric oxide is used to titrate the active sites in HDS catalysts [29,30]. This was not attempted due to the corrosive nature of nitric oxide.

\section{RESULTS AND DISCUSSION}

Table 1 summarizes some of the salient properties of the sulfide clusterderived catalysts. The HDS activities typically reached steady-state after ca. 30 min on stream. The activities and product distributions could be maintained for more than $24 \mathrm{~h}$ on stream with little or no detectable deactivation. Furthermore, the catalytic properties were reproducible through at least several reaction/reduction cycles. Arrhenius plots of the steady-state catalytic activities are illustrated in Fig. 3. Apparent activation energies for thiophene consumption ranged from 13.5 to $22.3 \mathrm{kcal} / \mathrm{mol}$. These values were similar to those reported for other HDS catalysts [31-33]. In addition, the $C_{4}$ and $C_{3}$ hydrocarbon apparent activation energies were similar suggesting a common reaction intermediate.

The reaction rates and turnover frequencies are compared in Table 2 . The 


\section{TABLE 1}

Properties of the catalysts

\begin{tabular}{llllc}
\hline $\begin{array}{l}\text { Catalyst } \\
\text { code }\end{array}$ & \multicolumn{2}{l}{ Loading (wt.-\%) } & $\begin{array}{l}\text { Cluster loading } \\
\left(\mu \mathrm{mol} / \mathrm{g}_{\text {cat }}\right)\end{array}$ & $\begin{array}{l}\mathrm{O}_{2} \text { uptake } \\
\left(\mu \mathrm{mol} / \mathrm{g}_{\text {cat }}\right)\end{array}$ \\
\cline { 2 - 3 } & $\mathrm{Mo}$ & $\mathrm{M}$ & & \\
\hline $\mathrm{MoS} / \mathrm{A}$ & 1.01 & 0.00 & 52.1 & 14.5 \\
$\mathrm{MoFeS} / \mathrm{A}$ & 0.63 & 0.37 & 33.0 & 6.5 \\
$\mathrm{MoCoS} / \mathrm{A}$ & 0.62 & 0.38 & 32.3 & 7.5 \\
$\mathrm{FeS} / \mathrm{A}$ & 0.00 & 1.00 & 89.5 & 15.1 \\
$\mathrm{CoS} / \mathrm{A}$ & 0.00 & 1.00 & 42.4 & 19.2 \\
MoS & - & - & - & 10.4 \\
Katalco & $8-11$ & $1-4$ & - & 108.1 \\
\hline
\end{tabular}

${ }^{\alpha}$ Pulsed chemisorption at $195 \mathrm{~K}$.

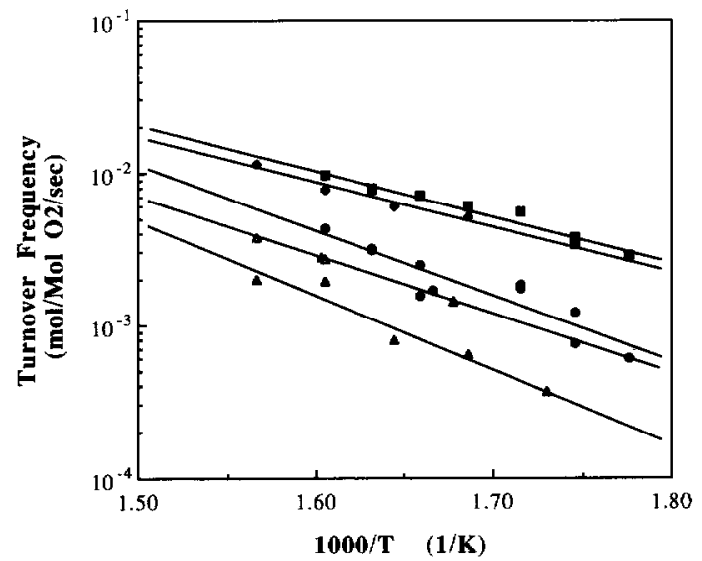

Fig. 3. Arrhenius plots of the thiophene HDS turnover frequencies measures at ca. $100 \mathrm{kPa}$ total pressure. Thiophene conversions were limited to $5 \%$. ( $\Delta$ ) MoS/A, (ם) MoCoS/A, (O) MoFeS/ A, ( $\bullet$ Katalco, ( $\Delta) \mathrm{MoS}_{2}$.

activities descended in the following order; $\mathrm{MoCoS} / \mathrm{A}>$ Katalco $>\mathrm{MoFeS} /$ $\mathrm{A}>\mathrm{MoS}_{2}>\mathrm{MoS} / \mathrm{A}>\mathrm{CoS} / \mathrm{A} \approx \mathrm{FeS} / \mathrm{A}$. This pattern is consistent with the order of activities reported for conventionally prepared metal sulfide catalysts [31-33]. There was some concern associated with the use of oxygen to titrate the active sites because both unpromoted and promoted HDS sites chemisorb oxygen [27]. The similarity between the cluster loading and the oxygen uptake suggested that the cluster-derived ensembles were highly, perhaps molecularly dispersed. Activities normalized by oxygen uptake therefore seemed appropriate at least for comparing the cluster-derived catalysts. The use of oxygen chemisorption for $\mathrm{MoS}_{2}$ has been well received $[27,28]$. For the Katalco catalyst we expected the reported turnover frequencies to be the lower limit of its 
TABLE 2

Catalytic properties, determined at $623 \mathrm{~K}$ and ca. $100 \mathrm{kPa}$

\begin{tabular}{|c|c|c|c|c|}
\hline \multirow[t]{2}{*}{ Catalyst } & \multirow{2}{*}{$\begin{array}{l}\text { Reaction rate } \\
\left(\mathrm{nmol} / \mathrm{g}_{\mathrm{cat}} \mathrm{s}\right)\end{array}$} & \multicolumn{2}{|c|}{ Turnover frequency $\left(\times 10^{4}\right)$} & \multirow{2}{*}{$\begin{array}{l}\Delta E_{\text {act }} \\
(\mathrm{kcal} / \mathrm{mol})\end{array}$} \\
\hline & & $\left(\mathrm{mol} / \mathrm{mol}_{\text {cluster }} \mathrm{s}\right)$ & $\left(\mathrm{mol} / \mathrm{mol}_{\mathrm{O}_{2}} \mathrm{~s}\right)$ & \\
\hline $\operatorname{MoS} / \mathrm{A}$ & 28.1 & 5.3 & 19.4 & 22.3 \\
\hline $\mathrm{MoFeS} / \mathrm{A}$ & 28.0 & 8.5 & 43.1 & 19.2 \\
\hline $\mathrm{MoCoS} / \mathrm{A}$ & 72.3 & 22.9 & 96.4 & 13.8 \\
\hline $\mathrm{FeS} / \mathrm{A}$ & 0.9 & 0.1 & 0.6 & $-\beta$ \\
\hline $\mathrm{CoS} / \mathrm{A}$ & 1.3 & 0.3 & 0.7 & ${ }^{\beta}$ \\
\hline $\mathrm{MoS}_{2}$ & 28.8 & - & 27.7 & 17.6 \\
\hline Katalco & 831.3 & - & 76.9 & 13.5 \\
\hline
\end{tabular}

${ }^{\alpha}$ Pulsed chemisorption at $195 \mathrm{~K}$.

${ }^{\beta}$ Low temperature activities too low to determine accurately.

activity. Nevertheless these turnover frequencies should be of the right order of magnitude so that rough comparisons can be made between the activities of Katalco and the other catalysts based on oxygen uptake.

The exceptional activities of the sulfide cluster-derived catalysts demonstrated that $\mathrm{MoS}_{2}$-like domains are not necessary for HDS activity. Consequently, the models that were discussed earlier do not adequately describe the important features of all HDS catalysts. It is possible that the sulfide clusters produced special sites that were different from the active sites in conventionally prepared HDS catalysts. However, similarities between the activities of the MoCoS/A and Katalco catalysts, and the MoS/A and $\mathrm{MoS}_{2}$ catalysts suggested that this was not the case. To the contrary one might conclude that the cluster-derived ensembles closely model the active sites in both promoted and unpromoted HDS catalysts. We propose that the active sites are actually molecularly dispersed ensembles that do not require $\mathrm{MoS}_{2}$-like domains. Information concerning the composition of these ensembles can be ascertained from comparisons of the activities of the cluster-derived catalysts.

By whatever measure the bimetallic sulfide clusters were precursors to more active catalysts than were the monometallic sulfide clusters. This suggested that strong, direct interactions between molybdenum and the promoter element are the basis for the promotional effect in HDS catalysis. Direct interactions would permit exchange of electron density between molybdenum and the promoter atom. Using a series of bimetallic nitrosyl complexes Topsøe et al. [34] explained the promotional effect of cobalt in terms of an increased electron density on neighboring molybdenum and sulfur atoms. Harris and Chianelli [35] proposed that cobalt and nickel are capable of donating electrons to molybdenum in certain types of Mo-M ensembles. These electronrich molybdenum sites might have enhanced HDS activities relative to the 
unpromoted site. Conversely acceptor atoms like copper are believed to extract electron density from molybdenum and poison the HDS site. Iron has been reported to have either a slightly promotional or poisoning effect [36,37]. We observed a very significant promotional effect for iron. In fact the MoFeS/A catalyst was twice as active as the MoS/A catalyst.

Similarities between the activities of the cluster-derived, Katalco and $\mathrm{MoS}_{2}$ catalysts indicated that dispersion had little influence on activity. This interpretation is consistent with molybdenum single crystal studies $[12,48]$. The sulfide clusters were much more efficient precursors for the production of active sites than molybdenum oxides generated using conventional precursors. For conventionally prepared catalysts the production of active sites depends primarily on the interaction between molybdenum oxide and the support [3840]. Strong interactions result in highly dispersed molybdenum oxide domains which are easily sulfided [38-40]. Weak interactions result in low dispersion of the molybdenum oxide. These large crystallites are difficult to sulfide and lead to a low activity catalyst. While it would be prohibitively expensive to use sulfide clusters as precursors to commercial catalysts, the development of less expensive mixed metal sulfide precursors is encouraged.

The primary products for thiophene HDS over most of the sulfide clusterderived catalysts were butenes and propene (Fig. 4). Small amounts of ethylene and ethane were also produced. The production of $\mathrm{C}_{2}$ and $\mathrm{C}_{3}$ hydrocarbons indicated that $\mathrm{C}-\mathrm{C}$ bonds were activated before $\mathrm{C}-\mathrm{S}$ bond hydrogenolysis. $\mathrm{A}$ $\pi$-bonded thiophenic intermediate would account for this behavior. This proposition was supported by tracer studies where tetrahydrothiophene HDS over

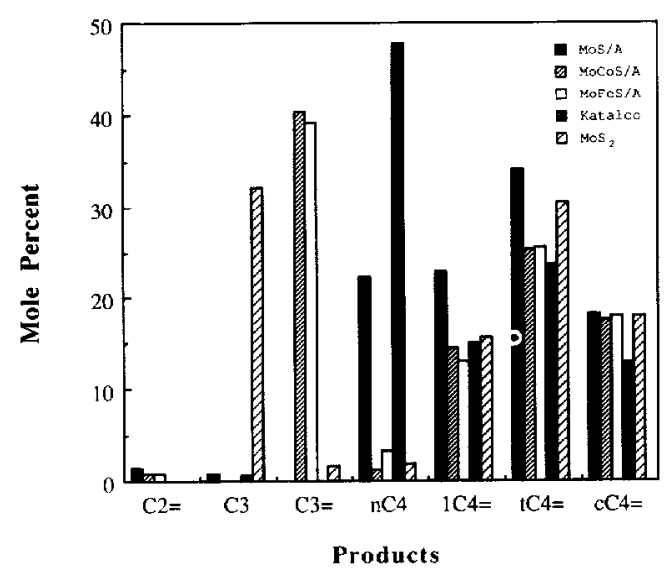

Fig. 4. Product distributions for thiophene HDS at $623 \mathrm{~K}$ and ca. $100 \mathrm{kPa}$ total pressure. Thiophene conversions were limited to $5 \%$. 
the cluster-derived catalysts also produced significant amounts of $\mathrm{C}_{2}$ and $\mathrm{C}_{3}$ hydrocarbons. Zdrazil [41] argued that the direct cleavage of aromatic C-S bonds would be very difficult. The $\mathrm{C}-\mathrm{C}$ and $\mathrm{C}-\mathrm{S}$ bonds in a hydrogenated $\pi$-bonded intermediate might have more similar probabilities for activation. Angelici and coworkers offer several examples of complexes with reactive $\pi$-bonded thiophenic ligands [42-46]. They demonstrated the synthesis of ruthenium and manganese $\pi$-bonded thiophenic complexes, and the feasibility of 2,3-dihydrothiophenic intermediates during HDS catalysis. Markel et al. [47] also suggested that thiophene HDS over sulfided $\mathrm{Mo} / \mathrm{Al}_{2} \mathrm{O}_{3} \mathrm{~m}$ and $\mathrm{Re} /$ $\mathrm{Al}_{2} \mathrm{O}_{3}$ catalysts proceeded through $\pi$-bonded hydrogenated thiophenic intermediates.

The primary products over the Katalco and MoS/A catalysts were a near thermodynamic equilibrium distribution of butenes and n-butane. The conversions were similar for each of the reaction rate measurements, so we do not believe that variations in conversion caused the differing product distributions. Subtly different properties of the active site precursors might account for the differences between the various product distributions.

There were no systematic relationships between the metal core compositions and the product distributions. Catalysts derived from clusters with metal cores consisting of $\mathrm{Mo}-\mathrm{Co}, \mathrm{Mo}-\mathrm{Fe}, \mathrm{Fe}$ and $\mathrm{Co}$ had similar product distributions. Other major differences between the clusters included the nature of their ligands and their structures. Catalysts derived from clusters containing sulfido ligands (including $\mathrm{FeS} / \mathrm{A}$ and $\mathrm{CoS} / \mathrm{A}$ ) produced significant amounts of $\mathrm{C}_{2}-\mathrm{C}_{3}$ hydrocarbons while those derived from clusters containing hydrosulfido ligands produced $\mathrm{C}_{4}$ hydrocarbons. Rakowski DuBois et al. [21] offer a pertinent example of the differing reactivities of hydrosulfido and sulfido complexes of the form $\left(\mathrm{CH}_{3}\right)_{n} \mathrm{C}_{5} \mathrm{H}_{5-n} \mathrm{Mo}_{2}(\mu-\mathrm{SH})_{2}(\mu-\mathrm{S})_{2}$ and $\left(\mathrm{CH}_{3}\right)_{n} \mathrm{C}_{5} \mathrm{H}_{5-n} \mathrm{Mo}_{2}(\mu-\mathrm{S})_{4}$. The hydrosulfido complexes catalyze the reduction of elemental sulfur to $\mathrm{H}_{2} \mathrm{~S}$ and HD exchange, and react with unsaturated hydrocarbons and thiols under mild conditions. The sulfido complex did not catalyze or participate in any of these reactions unless it was first converted to the hydrosulfido complex by reaction with hydrogen [24]. The nature of surface sulfur anions is also of fundamental importance in heterogeneous HDS catalysis [48,49]. By deduction and analogy we concluded that the character of the sulfide ligands in the precursor clusters at least partly influenced the product distributions. At this point we cannot comment on the influence of precursor cluster structure on the catalytic properties.

A reaction sequence that would account for the observed thiophene HDS product distributions has been proposed [17-19]. This reaction sequence which is illustrated in Fig. 5 is based on the presence of $\pi$-bonded thiophenic reaction intermediates. Results discussed in this paper are consistent with this model and implied that the character of sulfur in the active ensemble influenced the reaction pathway. Clearly additional research needs to be done, but our pro- 


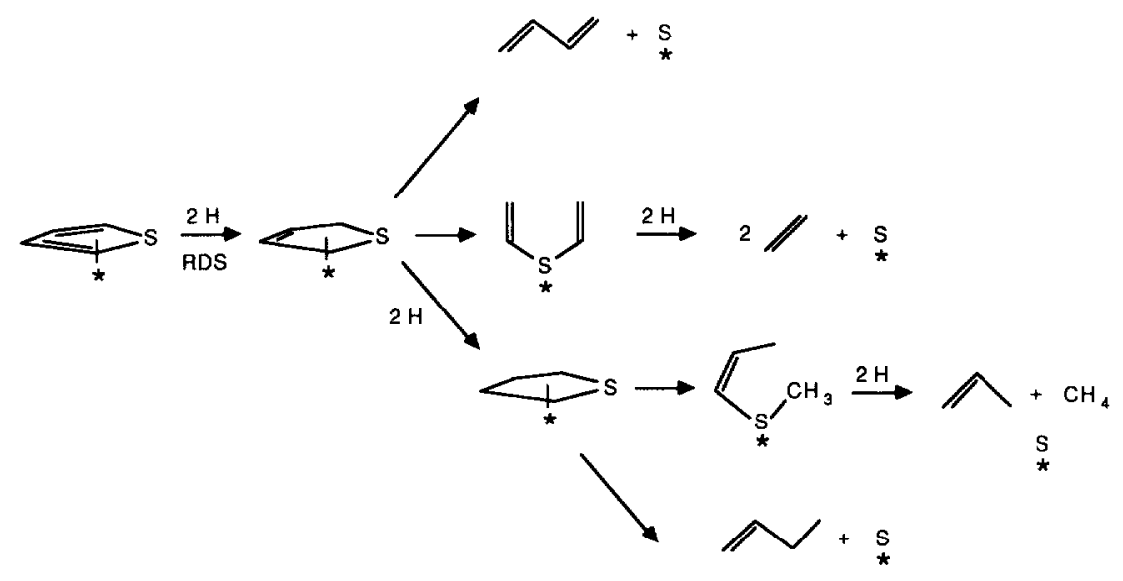

Fig. 5. Simplified schematic of a proposed reaction sequence for thiophene HDS [18, 19].

posal is consistent with the general character of both the sulfide cluster derived and conventionally prepared catalysts.

Characterization using XPS revealed that the electronic structure was relatively uniform for the cluster-derived catalysts, which for the MoFeS/A catalyst was in agreement with the Mössbauer spectroscopic results [17,19]. Keep in mind that the nature of the "working" active site might be different from the character determined under the ultra-high vacuum conditions required for XPS. Nevertheless some important information can be obtained as long as the catalyst is not exposed to air following pretreatment. X-ray photoelectron spectra were collected immediately following treatment of the catalyst in $2 \%$ $\mathrm{H}_{2} \mathrm{~S}$ in $\mathrm{H}_{2}$ at $673 \mathrm{~K}$ conditions selected to approximate the conditions used during activity measurements. The Mo(3d) spectra typically consisted of two envelopes which were deconvoluted to estimate the distribution of molybdenum oxidation states (Fig. 6). The curve fitting was constrained so that the peaks for each Mo $\left(3 d_{5 / 2}\right)$-Mo $\left(3 d_{3 / 2}\right)$ doublet had the same shape and width (FWHM). The relative intensities of spin-orbit doublet peaks are given by the ratio of their degeneracies [50]. For the $\mathrm{Mo}\left(3 \mathrm{~d}_{5 / 2}\right) / \mathrm{Mo}\left(3 \mathrm{~d}_{3 / 2}\right)$ doublet the intensity ratio would be $I\left(3 \mathrm{~d}_{5 / 2}\right) / I\left(3 \mathrm{~d}_{3 / 2}\right)=3 / 2$. A doublet splitting of ca. 3.15 $\mathrm{eV}$ was also expected. In the initial fit we assumed the presence of $\mathrm{Mo}^{0}, \mathrm{Mo}^{4+}$, $\mathrm{Mo}^{5+}$ and $\mathrm{Mo}^{6+}$. Much better fits were obtained when we also included a species with a Mo $\left(3 \mathrm{~d}_{5 / 2}\right)$ binding energy of $228.8 \pm 0.2 \mathrm{eV}$. The binding energy of this species was midway between those assigned to $\mathrm{Mo}^{4+}(230.0 \pm 0.2 \mathrm{eV})$ and $\mathrm{Mo}^{\circ}(227 . \pm 0.2 \mathrm{eV})$. While it has been suggested that binding energies near $228.9 \mathrm{eV}$ are characteristic of $\mathrm{Mo}^{2+}$, there are no reliable standards [51]. However, the binding energy of this species was similar to that of $\mathrm{Mo}^{2+}$ in $\mathrm{Mo}_{2} \mathrm{C}$ [52]. We denoted this species as $\mathrm{Mo}^{\delta+}$ where $0<\delta<4$. 


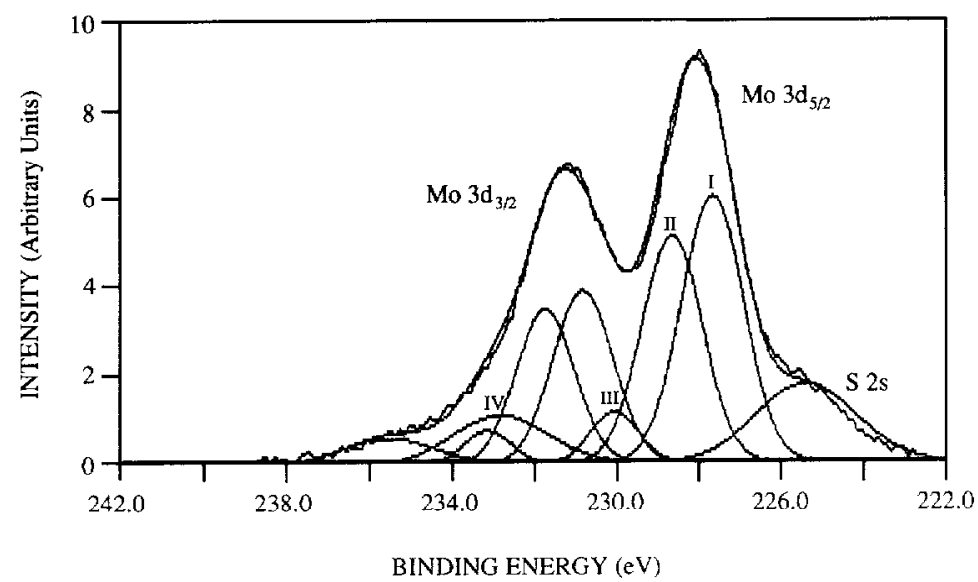

Fig. 6. X-ray photoelectron spectrum of MoS/A following reduction in flowing hydrogen at 673 K. Spectral deconvolution was constrained so that the peaks for each $\mathrm{Mo}\left(3 \mathrm{~d}_{5 / 2}\right)-\mathrm{Mo}\left(3 \mathrm{~d}_{3 / 2}\right)$ doublet had the same FWHM, an intensity ratio of $3: 2$, and a splitting of $3.15 \pm 0.2 \mathrm{eV}$. Peaks I, II, III and IV were assigned to $\mathrm{Mo}^{\circ}, \mathrm{Mo}^{\delta+}, \mathrm{Mo}^{4+}$ and $\mathrm{Mo}^{6+}$, respectively $(0<\delta<4)$.

TABIE 3

In situ XPS results

Spectra collected immediately following treatment in $2 \% \mathrm{H}_{2} \mathrm{~S}$ in $\mathrm{H}_{2}$ at $673 \mathrm{~K}$

\begin{tabular}{|c|c|c|c|c|}
\hline \multirow[t]{2}{*}{ Catalyst } & \multicolumn{4}{|c|}{ Mo $\left(3 d_{5 / 2}\right)$ Binding energy $(\mathrm{eV})$} \\
\hline & $\mathrm{Mo}^{0}$ & $\mathrm{Mo}^{\delta+}$ & $\mathrm{Mo}^{4+}$ & $\mathrm{Mo}^{6+}$ \\
\hline $\mathrm{MoS} / \mathrm{A}$ & $227.8(44)^{\alpha}$ & $228.8(36)$ & $230.1 \quad(6)$ & $232.9(13)$ \\
\hline $\mathrm{MoFeS} / \mathrm{A}$ & $227.8 \quad(2)$ & $228.8(77)$ & $230.2(10)$ & $232.5(11)$ \\
\hline $\mathrm{MoCoS} / \mathrm{A}$ & $227.9(62)$ & $228.9(21)$ & $230.3 \quad(8)$ & $232.9 \quad(9)$ \\
\hline $\mathrm{MoS}_{2}$ & $227.7 \quad(3)$ & $228.7(18)$ & $229.8(79)$ & \\
\hline Katalco & $227.5 \quad(9)$ & $228.7(73)$ & $230.2(10)$ & $232.9 \quad(9)$ \\
\hline
\end{tabular}

${ }^{\alpha}()=$ area percent.

The results of spectral deconvolution are given in Table 3. The uncertainties for the binding energies and peak areas were estimated to be $\pm 0.3 \mathrm{eV}$ and $\pm 10 \%$, respectively. The percentage of $\mathrm{Mo}^{6+}$ was similar to the percentage of hydroxyl groups on the surface of the $\gamma-\mathrm{Al}_{2} \mathrm{O}_{3}$ which was expected to be ca. $15 \%$. This suggested that a fraction of the clusters interacted with hydroxyls on the support surface to produce species containing irreducible molybdenum. Statistically significant amounts of $\mathrm{Mo}^{5+}$ were not detected in the catalysts. A significant amount of the $\mathrm{Mo}^{\delta+}$ species was present in the cluster-derived catalysts even immediately following preparation and exposure to air. The 
presence of highly reduced molybdenum in catalysts with such low loadings was unusual. This observation contrasts the character of conventionally prepared catalysts with similar loadings. In molybdate catalysts prepared from aqueous salt solutions, the first 1-2 wt.-\% molybdenum forms relatively stable oxides with or on the surface of the support [53]. Treatment in hydrogen and/ or hydrogen sulfide does not result in significant reduction beyond $\mathrm{Mo}^{4+}$.

For the sulfide cluster-derived catalysts the presence of strong metal-metal bonds and bridging sulfide ligands may have favored the production of stable, highly dispersed catalytic ensembles containing mostly $\mathrm{Mo}^{0}$ and $\mathrm{Mo}^{\delta+}$. In general, the use of organometallic clusters is an effective route to catalysts containing reduced molybdenum. Brown and Burwell [54] reported that the thermal decomposition and reduction of $\mathrm{Mo}(\mathrm{CO})_{6}$ sublimed onto partially dehydroxylated alumina resulted in the formation of highly dispersed molybdenum particles with average oxidation numbers of +1.9 to +5.7 as determined by oxygen titration. For dehydroxylated alumina they reported the production of molybdenum crystallites with average oxidation numbers of +0.3 to +1.0. More recently Goldwasser et al. [51] used XPS to get a more quantitative assessment of the molybdenum oxidation states. They observed that catalysts derived from the interaction of $\mathrm{Mo}(\mathrm{CO})_{6}$ with partially dehydroxylated alumina (ca. $20 \%$ surface hydroxyl content) followed by activation in helium at $573 \mathrm{~K}$ resulted in the formation of ca. $66 \% \mathrm{Mo}^{4+}$ and the balance $\mathrm{Mo}^{2+}$ (oxidation state was tentatively assigned). Metallic molybdenum crystallites and smaller amounts of $\mathrm{Mo}^{6+}$ and $\mathrm{Mo}^{4+}$ were formed on the surface of dehydroxylated alumina under the same preparative conditions. Clearly the nature of the interaction between the precursor and support affected the resting state of molybdenum in these catalysts but in most cases a significant amount of reduced molybdenum could be maintained.

Molybdenum chemistry is believed to have the dominant influence on the character of the active site for HDS. The molybdenum oxidation states of the catalysts studied in this work tracked roughly with their HDS activities. Zerovalent molybdenum appeared to be the dominant constituent in MoCoS/A, the catalyst with the highest activity. Approximately equal amounts of $\mathrm{Mo}^{0}$ and $\mathrm{Mo}^{\delta+}$ were implied for $\mathrm{MoS} / \mathrm{A}$ while $\mathrm{Mo}^{\delta+}$ accounted for almost $80 \%$ of the area for the $\mathrm{MoFeS} / \mathrm{A}$ and Katalco catalysts. As expected $\mathrm{MoS}_{2}$ contained mostly $\mathrm{Mo}^{4+}$ but a small amount of $\mathrm{Mo}^{\delta+}$ was also detected.

The average state of molybdenum reduction as estimated from the relative peak areas and oxidation states (assuming $\delta=2$ ) decreased as follows: MoCoS/ $\mathrm{A}>\mathrm{MoS} / \mathrm{A}>$ Katalco $>\mathrm{MoFeS} / \mathrm{A}>\mathrm{MoS}_{2}$. The same order would hold if we instead used the average molybdenum binding energy as an assessment of the state of reduction. This order was similar to the order of the HDS activities. The exception was MoS/A, which had a relatively low activity but high degree of reduction. The implication is that the character of the active site in promoted HDS catalysts is not solely determined by the molybdenum oxidation 
state. We believe that the promoted active site is not centered on molybdenum alone but instead on an ensemble containing molybdenum, the promoter element and sulfur. The nature of this ensemble remains to be determined but given that the average and local S/Mo and M/Mo atomic ratios near the surfaces of the catalysts were similar to those determined for their pure cluster precursors, the proposition of a Mo-M sulfide ensemble is justifiable. Some have suggested that the active site for HDS is centered on the promoter element [55]. We cannot support this proposal because the cobalt sulfide and iron sulfide cluster-derived catalysts had much lower activities than the other catalysts.

\section{CONCLUSIONS}

The sulfide clusters were precursors to thiophene HDS catalysts with activities that were comparable to that of Katalco 477, a commercial HDS catalyst. Unlike the commercial catalyst, the sulfide cluster-derived catalysts produced significant amounts of $\mathrm{C}_{2}$ and $\mathrm{C}_{3}$ hydrocarbons. This observation suggested that the reaction mechanism involved a $\pi$-bonded thiophenic intermediate with $\mathrm{C}-\mathrm{C}$ bond hydrogenolysis preceding $\mathrm{C}-\mathrm{S}$ bond cleavage. We also observed that the nature of the sulfide ligands in the clusters influenced the product distribution. Catalysts derived from clusters containing sulfido ligands produced $\mathrm{C}_{2}-\mathrm{C}_{3}$ hydrocarbons while catalysts derived from clusters containing hydrosulfido ligands produced mostly $\mathrm{C}_{4}$ hydrocarbons. A comparison of the properties of catalysts derived from complexes with different types of sulfide ligands but the same metal core will be the subject of a future study.

The activities of the MoCoS/A and MoFeS/A catalysts were much higher than the activity of the MoS/A catalyst. With the expectation that the bimetallic sulfide clusters would generate Mo-M sulfide ensembles, we concluded that the promotional effect in HDS catalysis is due in part to direct interactions between molybdenum and the promoter element. The $\mathrm{X}$-ray photoelectron spectroscopic results were consistent with this interpretation. We propose that the active sites in the sulfide cluster-derived HDS catalysts were highly dispersed ensembles containing reduced molybdenum $\left(\mathrm{Mo}^{\delta+}\right.$ and/or $\left.\mathrm{Mo}^{\circ}\right)$, the promoter element and sulfur. Similarities between the catalytic and spectroscopic properties indicate that sulfide cluster-derived ensembles are useful models of the active sites in commercial HDS catalysts. Our current efforts focus on describing in more detail the structural characteristics of these ensembles. On a practical level this information will assist in the design of improved hydrotreatment catalysts. We suggest that the performance of hydrotreatment catalysts can be enhanced by increasing the dispersion of the active constituents while maintaining intimacy between molybdenum, the promoter element and sulfur. Perhaps mixed metal sulfide precursor salts would be helpful in this effort. 


\section{ACKNOWLEDGEMENTS}

Financial support was provided by the National Science Foundation (ISI8760441) and the AMOCO Oil Company. The authors thank Professor M. David Curtis and Imad Bakkar for assistance in preparing the catalysts. BTC also wishes to acknowledge support provided by a National Science Foundation Fellowship.

\section{REFERENCES}

1 F.E. Massoth, J. Catal., 36 (1975) 164.

2 B. Delmon, Prep. Am. Chem. Suc. Div. Pet. Chem., 22(2) (1977) 503.

3 V.H. de Beer and G.C. Schuit, in B. Delmon, P. Jacobs and G. Poncelet (Editors), Preparation of Catalysts, Elsevier Science Publishers, New York, 1976, p. 343.

4 C. Wivel, R. Candia, B.S. Clausen, S. Mørup and H. Topsøe, J. Catal., 68 (1981) 453.

5 H. Topsøe and B.S .Clausen, Appl. Catal., 25 (1986) 273.

6 S. Mørup, B. Clausen and H. Topsøe, J. de Phys., 40(C2) (1979) 88.

7 R. Prins, V.H.J. de Beer and G.A. Somorjai, Catal. Rev.-Sci. Eng., 31 (1\&2) (1989) 1.

8 R.R. Chianelli, Catal. Rev.-Sci. Eng., 26 (3\&4) (1984) 361.

9 H. Topsøe and B.S. Clausen, Catal. Rev.-Sci. Eng., 26 (3\&4) (1984) 395.

10 P.J.H. Carnell, in M.V. Twigg (Fditor), Catalyst Handbook 2nd Edition, Wolfe Publishing, London, 1989, p. 205.

11 D.C. McCulloch, in B.E. Leach (Editor), Applied Industrial Catalysis Vol. 1, Academic Press, New York, 1983, p. 101.

12 A.J. Gellman, D. Neiman and G.A. Somorjai, J. Catal., 107 (1987) 92.

13 F. Zaera, E.B. Kollin and J.L. Gland, Surf. Sci., 184 (1987) 75.

14 M.A. Villa Garcia, J. Lindner, A. Sachdev and J. Schwank, J. Catal., 119 (1989) 388.

15 M.A. Villa Garcia, J. Lindner, A. Sachdev and J. Schwank, Appl. Catal., 56 (1989) 281.

16 M.E. Ekman, J.W. Anderegg and G.L. Schrader, J. Catal., 117 (1989) 246.

17 M.D. Curtis, J.E. Penner-Hahn, J. Schwank, O. Baralt, D. McCabe, L. Tompson and G. Waldo, Polyhedron, 7 (22/23) (1988) 2411.

18 L.T. Thompson and B.T. Carvill, in preparation.

19 L.T. Thompson, Ph.D. Dissertation, The University of Michigan, Ann Arbor, 1986, p. 101.

20 J.R. Brenner, B. Demczyk, A. Sachdev and L.T. Thompson, in preparation.

21 M. Rakowski DuBois, M.C. VanDerveer, D.L. Dubois, R.C. Haltiwanger and W.K. Miller, J. Am. Chem. Soc., 102 (1980) 7456.

22 P.D. Williams, M.D. Curtis, D.N. Duffy and W.M. Butler, Organometallics, 2 (1983) 165.

23 M.D. Curtis and P.D. Williams, Inorg. Chem., 22 (1983) 2661.

24 C.J. Casewit, D. Coons, L.L. Wright, W.K. Miller and M. Rakowski DuBois, Organometallics, 5 (1986) 951.

25 V.A. Uchtman and L.F. Dahl, J. Am. Chem. Soc., 91 (1969) 3756.

26 L.E. Bogan, D.A. Lesch and T.B. Rauchfuss, J. Organometallic Chem., 250 (1983) 429.

27 W. Zmierczak, G. Muralidhar and F.E. Massoth, J. Catal., 77 (1982) 432.

28 T.A. Bodrero and C.H. Bartholomew, J. Catal., 84 (1983) 145.

29 Z. Shuxian, W.K. Hall, G. Ertl and H. Knözinger, J. Catal., 100 (1986) 167.

$30 \quad$ K. Segawa and W.S. Millman, J. Catal., 101 (1986) 218.

31 T.A. Pecoraro and R.R. Chianelli, J. Catal., 67 (1981) 430.

32 R.R. Chianelli, T.A. Pecoraro, T.R. Halbert, W.H. Pan and E.I. Stiefel, J. Catal., 86 (1984) 226. 
33 B.C. Gates, J.R. Katzer and G.C.A. Schuit, Chemistry of Catalytic Processes, McGraw-Hill, NY, 1979, p. 390.

34 H. Topsøe, B.S. Clausen, N-Y Topsøe, E. Pedersen, W. Niemann, A. Müller, H. Bögge and B. Lengeler, J. Chem. Soc., Faraday Trans. 1, 83 (1987) 2157.

35 S. Harris and R.R. Chianelli, J. Catal., 98 (1986) 17.

36 D.S. Thakur, J. Catal., 94 (1985) 310.

37 S. Harris, Polyhedron, 5 (1986) 151.

38 G. Muralidhar, F.E. Massoth and J. Shabtai, J. Catal., 85 (1984) 44.

39 B. Scheffer, P. Arnoldy and J.A. Moulijn, J. Catal., 112 (1988) 516.

40 P. Arnoldy, J.A.M. van der Heijkant, G.D. de Bok and J.A. Moulijn, J. Catal., 92 (1985) 35.

41 M. Zdrazil, Collect. Czech. Commun., 40 (1975) 3491.

42 G.H. Spies and R.J. Angelici, Organometallics, 6 (1987) 1897.

43 J.N. Hachgenel and R.J. Angelici, Organometallics, 8 (1989) 1856.

44 Glavee, L.M. Daniels and R.J. Angelici, Organometallics, 8 (1989) 1856.

45 S.C. Huckett, N.N. Sauer and R.J. Angelici, Organometallics, 6 (1987) 591.

46 N.N. Sauer, E.J. Markel, G.L. Schrader and R.J. Angelici, J. Catal., 117 (1989) 295.

47 E.J. Markel, G.L. Schrader, N.N. Sauer and R.J. Angelici, J. Catal., 116 (1989) 11.

48 A.J. Gellman, M.E. Bussell and G.A. Somorjai, J. Catal., 107 (1987) 103.

49 P.R. Sarode, G. Sanakar, A. Srinivasan, S. Vasudevan, C.C.N.R. Rao and J.M. Thomas, Angew. Chem., 96 (1984) 288.

50 D. Briggs and M.P. Seah, Practical Surface Analysis by Auger and X-ray Photoelectron Spectroscopy, Wiley, NY, 1983.

51 J. Goldwasser, S.M. Fang, M. Houalla and W.K. Hall, J. Catal., 115 (1989) 34.

52 W.C. Moshier, G.D. Davis and G.O. Cote, J. Electrochem. Soc., 136 (1989) 356.

53 F.E. Massoth, Adv. Catal., 27 (1978) 265.

54 R.G. Brown and R.L. Burwell, Jr., J. Catal., 63 (1980) 463.

55 J.C. Duchet, E.M. van Oers, V.H.J. De Beer and R. Prins, J. Catal., 80 (1983) 386. 